\title{
Human Platelets Contain Brain-Derived Neurotrophic Factor
}

\author{
Hirotaka Yamamoto and Mark E. Gurney \\ Department of Cell, Molecular, and Structural Biology, Northwestern University Medical School, Chicago, Illinois 60611
}

\begin{abstract}
Neurotrophic support to peripheral sensory neurons is provided by 2 factors of related sequence, NGF and brain-derived neurotrophic factor (BDNF). NGF is present in peripheral target tissues, while BDNF has only been reported in the CNS. We now report the biological characterization and molecular cloning of a cDNA for BDNF from human platelets. BDNF in human platelets has biological activities very similar to those of BDNF obtained from adult porcine brain in neuronenriched cultures prepared from peripheral ganglia of chick embryos at 8-12 d of incubation. BDNF from human platelets promoted the survival and neurite outgrowth of placodal and neural crest-derived sensory neurons, but not to parasympathetic or sympathetic neurons. Activity of the factor was additive to that of NGF in dorsal root ganglia (DRG) neuron cultures and is equivalent to porcine brain BDNF in nodose ganglion neuron cultures. On SDS-PAGE, BDNF from human platelets is recovered at an apparent molecular weight equivalent to porcine brain BDNF (13,000 D). A BDNF cDNA fragment was amplified from human platelet RNA by using a coupled reverse transcriptase-polymerase chain reaction. Molecular cloning and DNA sequence analysis of the amplified cDNA fragment revealed complete identity for the deduced amino acid sequences of human and porcine BDNF [amino acid (aa) 10-108 of the mature factor]. Thus, human platelets might provide an important source of BDNF for regenerating peripheral sensory neurons at the site of nerve injury.
\end{abstract}

Sensory neurons of the PNS derive from 2 transient embryonic structures: the neural crest and the ectodermal placodes (LeDouarin, 1982). From the crest are formed the dorsal root sensory ganglia (DRG) along the spinal column and the sympathetic chain, and at a mesencephalic level, along the parasympathetic ganglia of the head. The ectodermal placodes contribute neurons to sensory ganglia located along the cranial nerves. The neurons comprising the various peripheral ganglia respond differentially to the neuronal growth factors thus far characterized: NGF, brain-derived neurotrophic factor (BDNF), neurotrophin-3 (NT3), ciliary neurotrophic factor (CNTF), and the fibroblast growth factors (FGFs; see Barde et al., 1982; Barbin et al., 1984; Davies, 1987; Unsicker et al., 1987; Maisonpierre et al., 1990). NGF,

\footnotetext{
Received Mar. 30, 1990; revised June 6, 1990; accepted June 7, 1990.

The authors thank Drs. Mark R. Lee and Gregory T. Spear for communicating their unpublished results and Ms. Briony P. Brian for providing technical assistance. The authors gratefully acknowledge R\&D Systems for providing human platelets. 'This work was supported by NIH grant P01-NS 21442 to M.E.G.

Correspondence should be addressed to Mark Gurney, Ph.D., Department of Cell, Molecular, and Structural Biology, Northwestern University Medical School, Ward Memorial Building, 303 East Chicago Avenue, Chicago, IL 60611.

Copyright (C) 1990 Society for Neuroscience $0270-6474 / 90 / 113469-10 \$ 03.00 / 0$
}

BDNF, and NT-3 are members of a gene family and share greater than 50\% homology (Hohn et al., 1990; Maisonpierre et al., 1990).

NGF and BDNF are highly homologous in amino acid sequence, though their spectrum of target neurons do not overlap. NGF, but not BDNF, supports the growth of sympathetic neurons in culture, while BDNF, but not NGF, supports the growth of placode-derived nodose sensory neurons in culture (Lindsay et al., 1985; Davies et al., 1986). High-affinity receptors for BDNF have been demonstrated on nodose neurons but are not expressed by sympathetic neurons (Rodrigeuz-Tebar and Barde, 1988). Both factors act on crest-derived sensory DRG neurons, but apparently on nonoverlapping populations, as well, as their effects in culture are additive. Crest-derived parasympathetic neurons of the ciliary ganglion respond to CNTF (Helfand et al., 1976; Barbin et al., 1984; Manthorpe et al., 1986) or to fibroblast growth factors (Unsicker et al., 1987) in culture, but not to BDNF or NGF. Like the FGFs, the polypeptide precursor of CNTF lacks a signal sequence and may not be actively secreted (Lin et al., 1989; Stockli et al., 1989). Unlike the FGFs, the biological activity of CNTF is not potentiated by heparin.

NGF has the best established role in vivo (Levi-Montalcini and Booker, 1960a,b). In most parts of the nervous system, more neurons are generated during embryonic development than will survive as development reaches completion. Sympathetic neurons and some sensory neurons within the DRG arc cxquisitely sensitive to NGF in vivo. Injection of exogenous NGF supports the survival of enhanced numbers of sympathetic and DRG sensory neurons (Hendry and Campbell, 1976; Hamburger et al., 1981), while blockade of NGF action by injection of antibodies to NGF decreases neuronal survival (Gorin and Johnson, 1979; Goedert et al., 1984). NGF has a similar action in vitro: sympathetic and DRG sensory neurons can be maintained in culture by addition of NGF to the culture medium, while the cultured neurons deprived of trophic support rapidly die due to an active death program (Martin et al., 1988).

Like NGF, a biological role for BDNF in vivo is becoming apparent. The neurons that respond to BDNF in culture, nodose neurons and a subpopulation of DRG neurons, can also be rescued by BDNF in vivo. During naturally occurring cell death, administration of exogenous BDNF can rescue DRG and nodose sensory neurons that otherwise would have died (Hofer and Barde, 1988).

Peripheral sensory neurons are proposed to receive neurotrophic support both from peripheral target tissues and from the CNS. NGF is present in the peripheral target tissues of sensory DRG neurons (Korsching and Thoenen, 1983), and interruption of its retrograde transport results in sensory neuron death (Johnson et al., 1986). BDNF is believed to be the centrally derived neurotrophic factor. Central rhizotomy of the DRG 
in newborn rats or avian embryos (Kalcheim et al., 1987) also results in the death of a proportion of the neurons (Yip and Johnson, 1984). BDNF has been shown to rescue avian DRG neurons in vivo that normally died after separation from the spinal cord, suggesting that it is a CNS-derived factor that is important in early development. Unlike NGF, BDNF mRNA is highly expressed in the adult CNS, but not in other tissues (Leibrock et al., 1989).

In the present study, we report that human platelets contain BDNF mRNA, as well as the mature factor, based on its biological and biochemical characterization. BDNF from human platelets supports the growth in culture of chick sensory nodose and DRG neurons and has the expected molecular weight on SDS-PAGE. Oligonucleotiode primers based on the nucleotide sequence of a pig BDNF cDNA (Leibrock et al., 1989) amplified a partial BNDF cDNA from human platelets using the polymerase chain reaction. Remarkably, the deduced partial amino acid sequence of human BDNF (99 residues of 120) has complete sequence identity to pig BDNF.

\section{Materials and Methods}

Dissociated neuron-enriched culture. Spinal lumbar DRG, nodose and sympathetic ganglia, and parasympathetic ciliary ganglia were dissected from White Leghorn chicken embryos that were incubated for 7 (E7) to $13 \mathrm{~d}$ (E13). Ganglia were collected into calcium and magnesium-free Hank's balanced salt solution (CMF-HBSS). The ganglia were cleaned of adherent tissue, then digested with $0.03-0.6 \%$ (w/v) trypsin (GIBCO), depending upon the age of the embryo, in CMF-HBSS for $15 \mathrm{~min}$ at $37^{\circ} \mathrm{C}$. Typically, $0.03 \%$ trypsin was used for digestion of E8 DRG and $0.07 \%$ for $\mathrm{E} 13$ nodose ganglia. Trypsin digestion was terminated by the addition of $1 / 10 \mathrm{vol}$ horse serum (HS). Ganglia were collected by centrifugation, rinsed once with F14 medium containing $10 \% \mathrm{HS}$, then resuspended in the same medium. The tissue was dispersed by gentle trituration, then brought up in $4 \mathrm{ml}$ medium. To enrich for neurons, the cells were layered on top of a cold, 4-ml metrizamide (Sigma) cushion, which was made up in PBS to a density of $1.063 \mathrm{gm} / \mathrm{ml}$ at room temperature. The cells were then centrifuged at $560 \times \mathrm{g}$ for $15 \mathrm{~min}$ at $4^{\circ} \mathrm{C}$. Neurons were collected in the pellet, rinsed once with medium containing $10 \% \mathrm{HS}$, then resuspended in the culture medium. Without metrizamide centrifugation, non-neuronal cell contamination was greater than $50 \%$ of the cells plated. After metrizamide centrifugation, nonneuronal cell number declined to $5-10 \%$ of the cells placed in culture. Cells were plated on poly-DL-ornithine- $(0.5 \mathrm{mg} / \mathrm{ml}$ in $150 \mathrm{~mm}$ sodium borate buffer) and laminin- (Collaborative Research, $50 \mu \mathrm{g} / \mathrm{ml}$ in PBS), coated 12-well tissue culture plates (Costar) at a density of 500-1000 cells $/ \mathrm{cm}^{2}$. Sympathetic neurons were plated without metrizamide separation. The culture medium consisted of F10 medium (Sigma) with $10 \%$ heat-inactivated HS (GIBCO) and F14 supplements. To accurately count the number of cells plated, squares enclosing $0.4 \mathrm{~cm} \times 0.75 \mathrm{~cm}$ of the central area in each culture well were scored on the bottom of the plate. Cultures were incubated at $37^{\circ} \mathrm{C}$ in an atmosphere of $5 \% \mathrm{CO}_{2}$ in humidified air. The numbers of cells in each well were counted after $1 \mathrm{hr}$ incubation to determine the number seeded per well. After 2 or 4 $\mathrm{d}$ growth in vitro, the numbers of neurons with or without processes greater than 5 cell diameters then were counted at a magnification of $100 x$

Culture media used were F10 with F14 supplements ( 4.9 mM glucose, $0.2 \mathrm{~mm}$ L-alanine, $10 \mu \mathrm{M}$ putrescine, $1.25 \mathrm{~mm}$ pyruvate, $100 \mu \mathrm{m}$ inositol, $0.1 \mathrm{~mm}$ choline-Cl, $1.22 \mathrm{~mm} \mathrm{CaCl}_{2}, 14.3 \mathrm{mM} \mathrm{NaHCO}_{3}$ ). N1 medium was F10/F14 medium supplemented with BSA/linoleic acid complex (Collaborative Research) at $100 \mu \mathrm{g} / \mathrm{ml}$, human transferrin (Sigma) at $100 \mu \mathrm{g} / \mathrm{ml}, 0.19 \mu \mathrm{M}$ progesterone, $0.1 \mathrm{~mm}$ putrescine, and $0.3 \mu \mathrm{M}$ selenous acid ( $\mathrm{Na}$ salt). Penicillin was included at $100 \mathrm{U} / \mathrm{ml}$, and streptomycin at $100 \mu \mathrm{g} / \mathrm{ml}$.

Platelet extracts or partially purified factors were tested for effects on E8, E9, E10, and E12 DRG neurons, E8, E9, and E1 3 nodose neurons, E9 ciliary neurons, and E12 sympathetic neurons. As positive controls, DRG and sympathetic neurons were grown with NGF, and sensory and ciliary neurons were grown with partially purified BDNF and CNTF, respectively.
Preparation of factors. BDNF was partially purified from adult porcine brain according to the method of Lindsay et al. (1985) by acid precipitation and chromatography over CM-cellulose (Whatman) and hydroxylapatite (BioRad) to a specific activity of $2 \mu \mathrm{g}$ protein $/ \mathrm{ml}$ for maximal neurite extension by cultured DRG neurons. Partially purified CNTF was prepared according to the method of Barbin et al. (1984) from E8-E14 embryonic chick eyes by chromatography over DEAEcellulose (Whatman). Human platelet-derived growth factor (hPDGF), acidic fibroblast growth factor (aFGF), and basic fibroblast growth factor (bFGF) were purchased from R\&D Systems, and NGF was purchased from Sigma Chemical Company.

To prepare human platelets, blood was collected from healthy adult donors in heparinized tubes and diluted into an equal volume of CMFHBSS containing $1 / 5$ vol $200 \mathrm{mM} \mathrm{Na}_{2}$ EDTA, $145 \mathrm{~mm} \mathrm{NaCl}$, and 25 mM Tris buffer (pH, 6.6) (TEN buffer). Platelets were handled at room temperature. Nucleated cells were pelleted by low-speed centrifugation at $200 \times g$ for $15 \mathrm{~min}$, the platelet-rich supernatant was collected and the platelets pelleted by centrifugation at $1300 \times g$ for $10 \mathrm{~min}$, then the platelet pellet was washed twice with CMF-HBSS/TEN buffer. Platelets from the rabbit, pig, and calf were prepared in the same manner. Contamination of the platelet fraction by nucleated cells ranged from 6 to $8 \%$ as assessed with a particle counter (Coulter Model ZF).

For extraction, $100 \mathrm{mg}$ wet-weight platelets (from approximately 100 $\mathrm{ml}$ hlood) were homogenized with a Teflon-glass homogenizer in $2 \mathrm{ml}$ distilled water and centrifuged at $45,000 \times g$ for $20 \mathrm{~min}$. The extract contained $14 \mathrm{mg}$ protein and was used for the culture assays described in the following text.

Partial purification of BDNF from platelets by cation-exchange chromatography. Concentrated sodium phosphate buffer $(\mathrm{pH}, 6.0)$ was added to a volume of platelet extract containing $100 \mathrm{mg}$ protein to bring the solution to $10 \mathrm{~mm}$ sodium phosphate. This was loaded onto a CMsepharose 4B column (Pharmacia; dimensions, $1.6 \times 10 \mathrm{~cm}$ ) previously equilibrated to $10 \mathrm{~mm}$ sodium phosphate buffer $(\mathrm{pH}, 6.0)$. The column was washed with $10 \mathrm{~mm}$ sodium phosphate until unbound protein was eluted, then with 10 column volumes $10 \mathrm{~mm}$ sodium phosphate buffer containing $0.3 \mathrm{M} \mathrm{NaCl}$. BDNF was eluted with phosphate buffer containing $0.5 \mathrm{M} \mathrm{NaCl}$, and active fractions were identified by bioassay with DRG neurons, then pooled and concentrated with an Amicon YM10 membrane.

Factors were used for cultures at concentrations that elicited maximal neurite outgrowth and survival unless otherwise noted. Typically, partially purified pig brain BDNF was used at $2 \mu \mathrm{g} / \mathrm{ml}$, the $0.5 \mathrm{M} \mathrm{NaCl}$ CM-sepharose eluate containing partially purified human platelet BDNF was used at $300 \mathrm{ng} / \mathrm{ml}$, and purified NGF was used at $10 \mathrm{ng} / \mathrm{ml}$. Protein concentration was measured with the Bio-Rad protein assay.

SDS-Page. SDS-polyacrylamide gels contained $14 \%$ acrylamide and $0.134 \%$ bis-acrylamide. Usually, $150-200 \mu \mathrm{g}$ protein from platelet extract was loaded per gel lane in $0.24 \mathrm{M}$ Tris-Cl sample buffer $(\mathrm{pH}, 6.8)$ without SDS or reducing agent. Gels were electrophoresed overnight at $8 \mathrm{~mA}$ per $1.5-\mathrm{mm}$-thick gel. Rhodamine-conjugated cytochrome $\mathrm{C}$ was used as a colored indicator of molecular weight. Gels were sliced at $2-\mathrm{mm}$ intervals across 6 lanes of loaded protein. The gel slices were macerated, then extracted for up to $4 \mathrm{~d}$ in $300 \mu 13 \%$ BSA in CMFHBSS at $4^{\circ} \mathrm{C}$. Two hundred $\mu \mathrm{l}$ extract was separated from the gel fragments by centrifugation, and $100 \mu \mathrm{l}$ of each extract was bioassaycd on cultures of DRG or nodose neurons.

Detection of BDNF MRNA in human platelets by reverse transcriptasepolymerase chain reaction ( $R T-P C R)$. Total RNA of human platelets was isolated as described (Newman et al., 1988). In 1 experiment, RNA was isolated from platelets obtained in $240 \mathrm{ml}$ fresh blood, and in a second experiment, 1 Unit of platelets obtained from a local blood bank was used. Platelets were pelleted by centrifugation, then solubilized in $8 \mathrm{ml}$ buffer containing $4 \mathrm{M}$ guanidium isothiocyanate, $5 \mathrm{~mm}$ sodium citrate, $0.1 \mathrm{M} 2$-mercaptoethanol, $0.5 \%$ Sarkosyl, $0.1 \%$ Antifoam $A$ and RNasin (Promega) at $40 \mathrm{U} / \mathrm{ml}$. Then the platelets were layered onto a 1.5-ml cushion of $5.7 \mathrm{M}$ cesium chloride and centrifuged in an SW 41 rotor (Beckman) at $25,000 \mathrm{rpm}$ for $16 \mathrm{hr}$. The RNA pellet was resuspended in $10 \mathrm{mM}$ Tris $(\mathrm{pH}, 8)$ and $1 \mathrm{mM} \mathrm{Na}{ }_{2}$ EDTA (TE buffer), then precipitated with ethanol. As a positive control, polyA ${ }^{+}$RNA also was isolated from a human astrocytoma cell line, U-87 MG, and from mouse brain according to the manufacturer's instruction (mRNA isolation kit, Invitrogen). Oligonucleotides were synthesized with $\beta$-cyanoethyl phosphoramidite chemistry on an Applied Biosystems 381A DNA synthesizer using trityl-off synthesis. The oligonucleotide was cleaved and deprotected with ammonium hydroxide, then purified over Sephadex 
Table 1. PCR primers for amplification of BDNF sequences

\begin{tabular}{llll} 
Primer & Sequence $\left(5^{\prime}-3^{\prime}\right)$ & $\begin{array}{l}\text { Location } \\
\text { in porcine } \\
\text { BDNF cDNA }\end{array}$ & DNA strand \\
\hline 1 & GTGTGCGACAGCATTAGCCAGTGG & $(599-622)$ & sense \\
2 & GACCCCGCCCGCCGCGGGGAG & $(572-592)$ & sense \\
3 & CCTCTTAATGGTCAAAGTACATACAC & $(916-891)$ & antisense \\
4 & AGTGTCTATCCTTATGAACCGCC & $(886-864)$ & antisense \\
\hline
\end{tabular}

G-25 equilibrated to TE buffer. Oligonucleotide primers for RT-PCR were based on the published nucleotide sequences of human NGF and porcine BDNF (Table 1, Fig. 6). The template for cDNA synthesis was either $2.3 \mu \mathrm{g}$ total RNA from platelets or $0.5 \mu \mathrm{g}$ polyA ${ }^{+}$RNA from $\mathrm{U}-87 \mathrm{MG}$ cells or mouse brain. To perform the cDNA synthesis, $25 \mu \mathrm{l}$ reaction mixture containing $50 \mathrm{~mm}$ Tris- $\mathrm{HCl}(\mathrm{pH}, 8.3), 75 \mathrm{~mm} \mathrm{KCl}, 3$ mм $\mathrm{MgCl}_{2}, 10 \mathrm{~mm}$ dithiothreitol (DTT), $0.5 \mathrm{~mm}$ each of dATP, dGTP, $\mathrm{dCTP}$, and dTTP (dNTPs), $10 \mathrm{U}$ RNasin (Promega), and $1 \mu \mathrm{g}$ random primer (for poly $\mathrm{A}^{+}$template) or oligodeoxythymidine (oligo $\mathrm{dT}$ ) primer (for platelet RNA template) was incubated with $100 \mathrm{U}$ Moloney Murine Leukemia Virus (M-MLV) reverse transcriptase (Bethesda Research Laboratories) at $42^{\circ} \mathrm{C}$ for $1 \mathrm{hr}$. The cDNA reaction mixture was diluted with an equal vol PCR buffer containing $10 \mathrm{~mm}$ Tris- $\mathrm{HCl}(\mathrm{pH}, 8.3), 50$ $\mathrm{mm} \mathrm{KCl}, 5 \mathrm{~mm} \mathrm{MgCl}_{2}, 0.01 \%$ (w/v) gelatin, $0.8 \mathrm{~mm}$ of each dNTP, 50 pmol of either primer (see above), and 1.5 U Taq polymerase. Amplification was performed on a programmable heater (Techne). The reaction cycle consisted of denaturation at $94^{\circ} \mathrm{C}$ for $0.3 \mathrm{~min}$, annealing at $53^{\circ} \mathrm{C}$ for $0.5 \mathrm{~min}$, and elongation at $68^{\circ} \mathrm{C}$ for $0.5 \mathrm{~min}$. After 35 cycles, aliquots of the PCR reactions were electrophoresed on $1 \%$ agarose gels. As a control for contamination of the platelet RNA by human genomic DNA, PCR amplifications were performed that included every reagent except for the M-MLV RT.

To clone the PCR product into an M13 vector for DNA sequencing, amplified DNA bands of the expected size were recovered from the agarose gel, then phosphorylated with $\mathrm{T} 4$ polynucleotide kinase. The DNA fragment was then ligated into a Smal cut and dephosphorylated M13mp8 vector and transformed into JM109 cells. The sequence of the DNA insert was determined by dideoxynucleotide sequencing (Sequenase, U.S. Biochemical).

\section{Results}

\section{Detection of BDNF biological activity in human platelets}

BDNF biological activity was detected in human platelets in initial experiments designed to examine the release of neurotrophic factors by human peripheral blood mononuclear cells (MNCs). MNCs were isolated by centrifugation on Ficoll-Hypaque, then stimulated by $18 \mathrm{hr}$ culture with phytohemagglutinin, pokeweed mitogen, or lipopolysaccharide (LPS) according to standard protocols (Gurney et al., 1986). The supernatant medium was collected from the cultures, then tested for neurotrophic support of E10 DRG neurons. LPS-stimulated MNCculture supernatants promoted the growth of cultured DRG neurons, while supernatants from the lectin-stimulated $\mathrm{MNC}$ cultures were without effect. The source of neurotrophic activity was eventually traced to the platelet fraction and could be released by extraction of human platelets with distilled water. Among the species tested, extracts of human platelets contained greater neurotrophic activity than those of the rabbit or pig. No activity was detected in extracts of bovine platelets.

Characterization of the types of peripheral neurons responsive to the platelet extract revealed a spectrum of biological activity similar to that of BDNF (Lindsay et al., 1985; Davies et al., 1986; Davies, 1987). Preliminary characterization of the neurotrophic activity in human platelets revealed that nodose and DRG sensory neurons were responsive to the platelet extract, while no response was shown by sympathetic or ciliary neurons (as in Figs. 1, 2). Autonomic neurons of sympathetic ganglia and of ciliary ganglia were responsive to NGF and to a factor in embryonic eye extract, respectively, but were not responsive to the platelet extract (Fig. 2).

The neurotrophic activity of the platelet extract was completely lost after boiling for 2 min or after treatment with trypsin. For the trypsin inactivation experiment, $50 \mu \mathrm{l}$ platelet extract $(0.4 \mathrm{mg}$ protein $/ \mathrm{ml})$ was digested with $0.05 \%(\mathrm{w} / \mathrm{v})$ trypsin for $2 \mathrm{hr}$ at $37^{\circ} \mathrm{C}$. The digest was then diluted 40 -fold into medium containing $10 \% \mathrm{HS}$ to give a final platelet extract concentration of $10 \mu \mathrm{g} / \mathrm{ml}$ in $10 \% \mathrm{HS}$ and a negligible trypsin concentration of $0.0012 \%$. The neurotrophic activity in the platelet extract was completely eliminated when bioassayed with nodose neurons, which suggested that the neurotrophic activity was due to 1 or more proteins in the extract.

We also tested whether or not human PDGF and basic or acidic FGF could account for the neurotrophic activity observed in platelet extracts. Neither DRG nor nodose neurons could be maintained in culture by hPDGF at 1 or $10 \mathrm{ng} / \mathrm{ml}$ or by aFGF tested at 10,25 , and $50 \mathrm{ng} / \mathrm{ml}$. At the same concentrations, bFGF showed weak neuritogenic and survival activity on E9 nodose neurons. The potency of bFGF was, however, different from that of the factor in human platelets, as less than $5 \%$ of nodose neurons plated could be maintained in culture with bFGF compared to $20-30 \%$ with addition of the platelet extract.

\section{Partial purification of $B D N F$ from platelets}

In both DRG and nodose sensory neuron cultures, dose-response curves were similar with $1 / 2$ maximum neurite outgrowth obtained with the platelet extract added at a concentration of approximately $1-2 \mu \mathrm{g}$ protein per $\mathrm{ml}$ in serum-free $\mathrm{Nl}$ medium. Maximum neurite outgrowth was obtained with the extract at 4-6 $\mu \mathrm{g}$ protein per $\mathrm{ml}$ in $\mathrm{N} 1$ medium and 12-16 $\mu \mathrm{g}$ protein per $\mathrm{ml}$ in $\mathrm{F} 10 / 14$ medium supplemented with $10 \% \mathrm{HS}$. Preliminary chromatography of the platelet extract over CM-cellulose at $\mathrm{pH}$ 6.0 or DEAE-cellulose at $\mathrm{pH} 8.0$ (both in $10 \mathrm{~mm}$ sodium phosphate buffer) indicated that the neurotrophic activity was absorbed onto the cation exchanger as expected for BDNF (Barde et al., 1982). On chromatography of $100 \mathrm{mg}$ platelet-extract protein over CM-sepharose, a small amount of neurotrophic activity was recovered in the column flow-through, and no neurotrophic activity was eluted with a low-salt wash $(0.3 \mathrm{M} \mathrm{NaCl}$ in $10 \mathrm{~mm}$ sodium phosphate buffer at $\mathrm{pH} 6.0$ ), while the majority of loaded activity was recovered in the high-salt eluate $(0.5 \mathrm{M}$ $\mathrm{NaCl}$ in sodium phosphate buffer). One-half maximum neurotrophic activity for the $0.5 \mathrm{M} \mathrm{NaCl}$ eluate was achicved at a protein concentration of $30 \mathrm{ng} / \mathrm{ml}$ in $\mathrm{Nl}$ medium, which is an approximately 50 -fold increase in specific activity over the platelet extract. Recovery of neurotrophic activity was estimated 

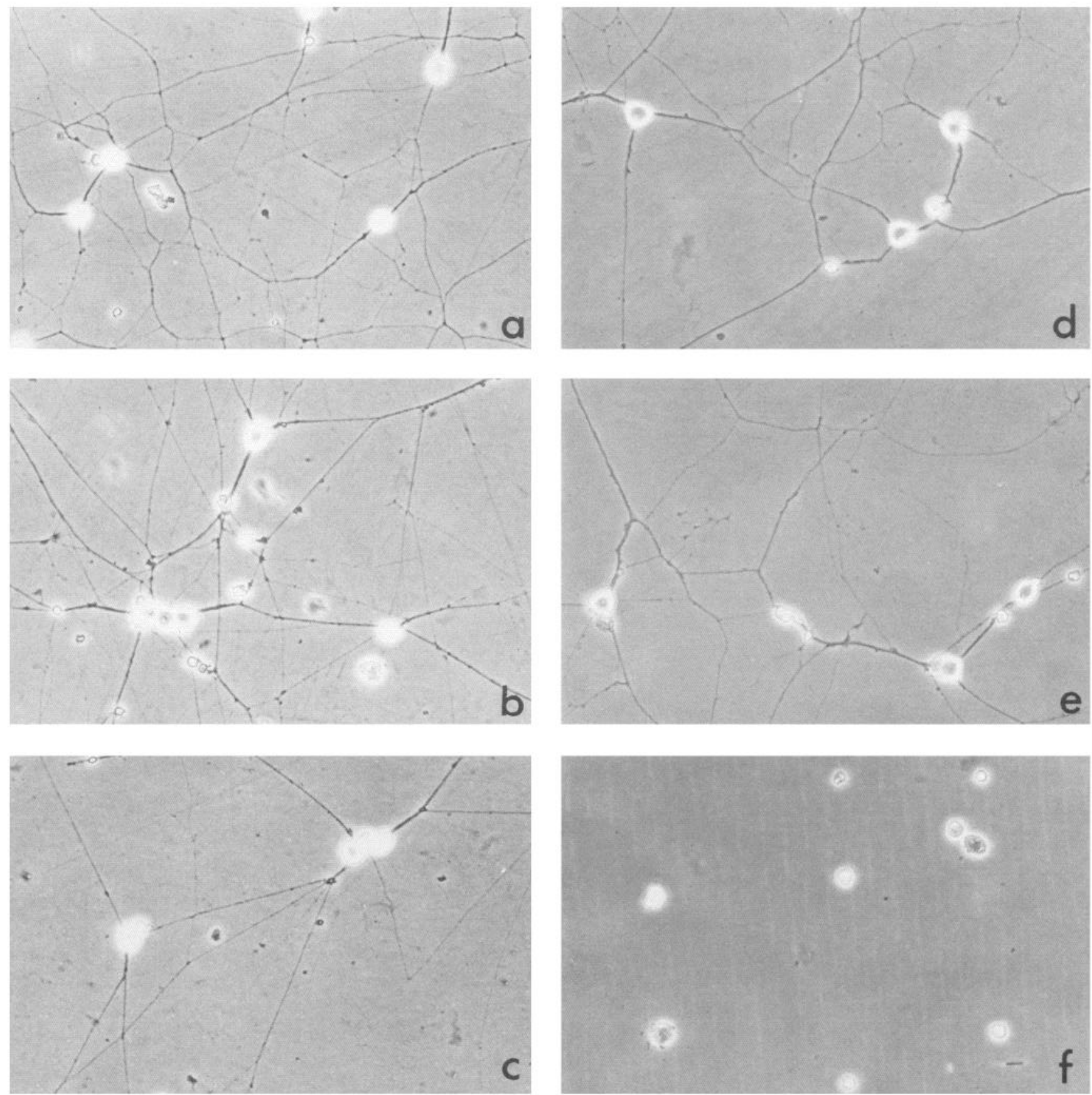

Figure 1. Phase-contrast micrographs of dissociated neuron-enriched cultures of E9 DRG and nodose neurons. DRG neurons were cultured with NGF $(a)$ for $2 \mathrm{~d}$, with partially purified pig brain $\operatorname{BDNF}(b)$ for $6 \mathrm{~d}$, and with the CM-sepharose fraction containing partially purified human platelet BDNF (300 ng protein/ml) for $6 \mathrm{~d}(c)$. Nodose neurons cultured with partially purified pig brain BDNF $(d)$ for $6 \mathrm{~d}$, partially purified platelet BDNF $(e)$ for $6 \mathrm{~d}$ and without addition of neurotrophic factors in basal medium for $4 \mathrm{~d}(f)$. Note that few non-neuronal cells were present in the cultures after fractionation of the cells on metrizamide. Cells were grown on a polyornithine/laminin substrate in F10/14 medium containing $10 \%$ heat inactivated HS.

to be $30 \%$. For routine cultures, $300 \mathrm{ng} / \mathrm{ml}$ of partially purified platelet BDNF was used for each assay, and this showed the full activity obtained with the platelet extract.

\section{Comparison of platelet BDNF with pig brain BDNF}

The survival of E9 neurons from the DRG or nodose ganglia without the addition of neurotrophic factors to the culture medium was very low by $4 \mathrm{~d}$ in culture (Fig. $3 a, b$ ). NGF (on DRG neurons only), pig brain BDNF, and human platelet BDNF demonstrated an increasing effect on survival of process-bearing neurons with longer culture periods. By $4 \mathrm{~d}$, neuritogenic and survival activity were closely related as DRG or nodose sensory neurons without processes preferentially died. Platelet BDNF had $1 / 2$ the neuritogenic activity of NGF and equal potency with BDNF on E9 DRG neurons after $4 \mathrm{~d}$ in culture (Fig. $3 a$ ). On nodose neurons, the neurite outgrowth and survival were slightly higher with pig brain BDNF than with human platelet BDNF (Fig. $3 b$ ). These results suggested that long-term survival of both 


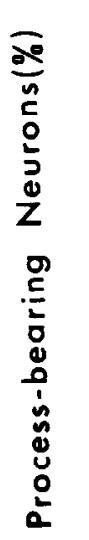

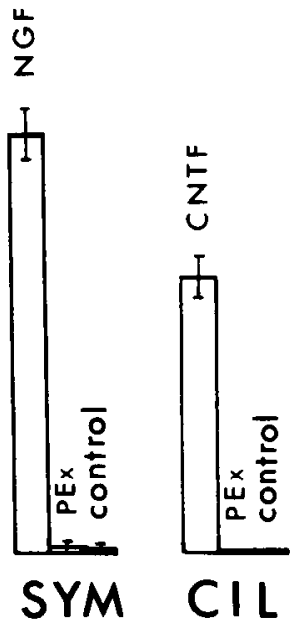

Figure 2. BDNF from human platelets supports placode and neural crest-derived sensory neurons, but not autonomic neurons in dissociated cell culture. Neurons from E9 $D R G$, E9 nodose ganglia $(N G)$, E12 sympathetic ganglia $(S Y M)$, and E9 ciliary ganglia $(C I L)$ were cultured with NGF $(10 \mathrm{ng} / \mathrm{ml})$, partially purified pig brain BDNF $(2 \mu \mathrm{g} / \mathrm{ml})$, chick embryonic eye extract $(100 \mu \mathrm{g} / \mathrm{ml})$, partially purified platelet BDNF (platelet-CM, $300 \mathrm{ng} / \mathrm{ml}$ ), or human platelet extract $(20 \mu \mathrm{g} / \mathrm{ml}$ ). Processbearing DRG and nodose neurons were counted after $4 \mathrm{~d}$ in culture. Process-hearing autonomic neurons from E12 sympathetic ganglia and E9 ciliary ganglia were counted after $2 \mathrm{~d}$ in culture ( $n=4$; values are mean $\pm \mathrm{SD}$ ). No neutrophic activity was detected in the platelet extract in bioassays with autonomic neurons.

DRG and nodose neurons in response to added BDNF from pig brain or human platelets was similar and was associated with neurite outgrowth (Fig. $3 a, b$ ).

It has been previously shown that the survival effects of NGF and pig brain BDNF are strictly additive in cultures of late embryonic E12 DRG neurons (Lindsay et al., 1985). A similar result was obtained when human platelet BDNF was tested alone or in combination with NGF. The 2 factors had an additive effect when tested on E10 DRG neurons (Fig. 4). No additivity was observed with pig brain and human platelet BDNF tested in combination on nodose sensory neurons, which confirmed their biological equivalence.

\section{Apparent molecular weight of platelet BDNF determined by $S D S-P A G E$}

To establish the apparent molecular weight of platelet BDNF, the platelet extract was subject to SDS-PAGE ( $14 \%$ acrylamide, $0.135 \%$ bis-acrylamide gels) together with the molecular weight markers carbonic anhydrase $(29,000 \mathrm{Da}), \beta$-lactoglobulin $(18,400$ $\mathrm{Da})$, lysozyme $(14,300 \mathrm{Da})$, and cytochrome $\mathrm{C}(12,500 \mathrm{Da})$. The cytochrome $C$ was labeled with rhodamine $B$ isothiocyanate to provide a colored marker with which to identify gel slices of interest. Neurotrophic activity for cultured DRG and nodose neurons consistently comigrated with rhodaminc-conjugatcd cytochrome $\mathrm{C}$ at an apparent $M_{\mathrm{r}}$ of 13,000 Da (Fig. 5), which is similar to the apparent molecular weight on SDS-PAGE reported for pig brain BDNF (Barde et al., 1982) and deduced from the pig brain BDNF cDNA (Leibrock et al., 1989). Neurotrophic activity was eluted from the sliced gel as a single peak with an identical mobility when bioassayed on either cultured DRG or nodose neurons. No activity of a possible dimer of 20,000-30,000 Da was observed in the SDS-PAGE experiments. Platelet BDNF showed the same potency (i.e., neuritogenic activity or numbers of neurons surviving at the
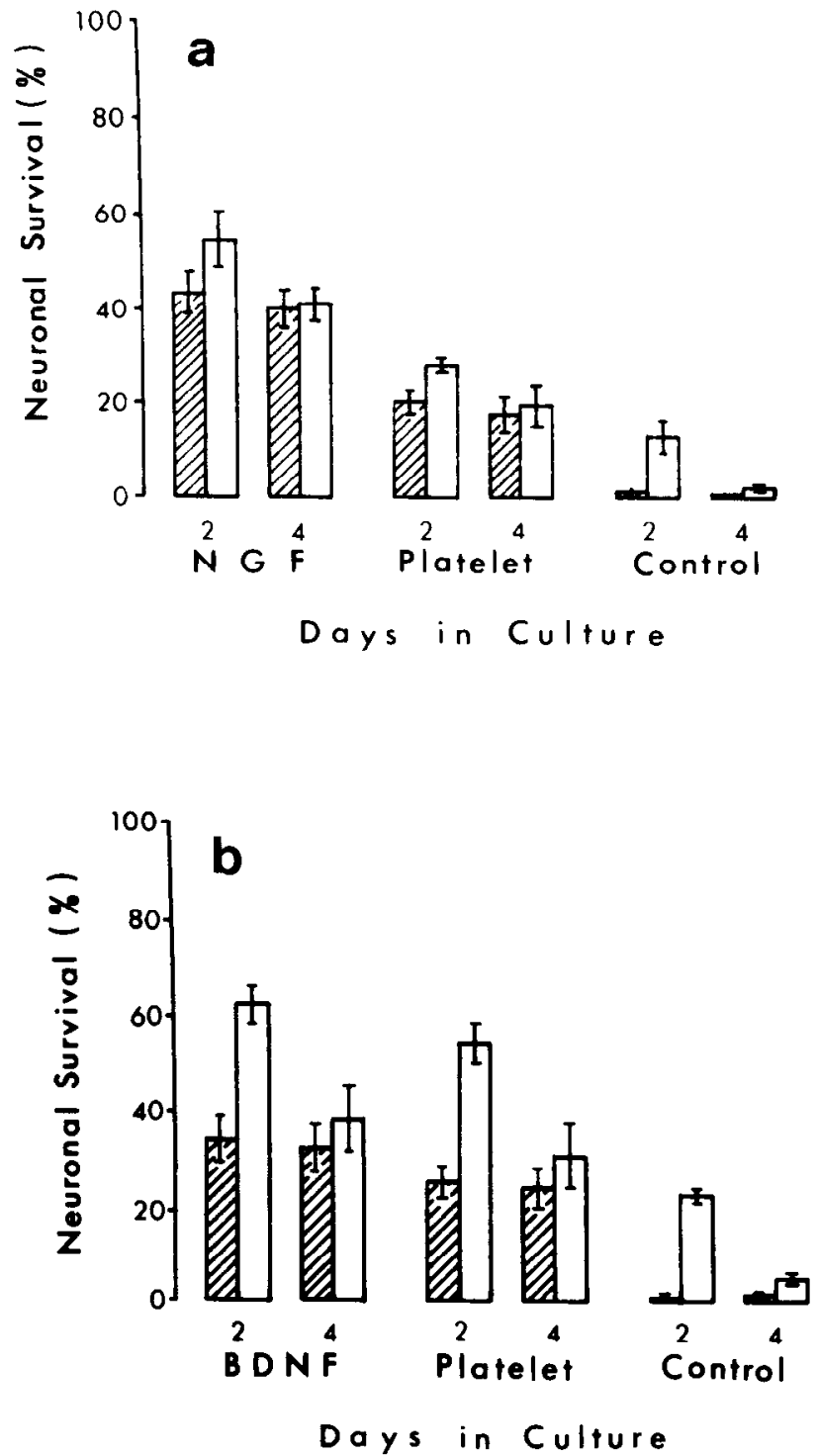

Figure 3. Effect of NGF, pig brain BDNF, and human platelet BDNF on survival and ncurite outgrowth of E9 DRG $(a)$ or nodose neurons (b). Numbers of viable phase-bright cells (open bars) and neurons with long processes (hatched bars) were counted after 2 and $4 \mathrm{~d}$ culture in F14 medium supplemented with $10 \%$ HS ( $n=4$ for each treatment; values are mean $\pm \mathrm{SD}$ ). Phase-bright cells without processes (given by the difference between the open and hatched bars) survived $2 \mathrm{~d}$ in the control cultures but had died by $4 \mathrm{~d}$. Neurons with long processes (hatched bars) cultured in the presence of NGF, pig brain BDNF, or platelet BDNF survived for $4 \mathrm{~d}$. The percentage of process-bearing DRG neurons that responded to platelet BDNF was $1 / 2$ the number that responded to NGF. For all treatments, counts of process-bearing neurons were similar after 2 and $4 \mathrm{~d}$ in culture, while cell death was preferentially associated with neurons that failed to extend processes.

concentration of maximum effect), whether partially purified by SDS-PAGE or by CM-sepharose chromatography, as compared to the platelet extract.

\section{Molecular cloning of human BDNF CDNA from platelet RNA}

Platelets are shed in the bone marrow from the megakaryocyte. Although platelets lack a nucleus, they contain megakaryocyte cytoplasm and hence small amounts of cytoplasmic RNA. The vestigial amount of RNA present is sufficient for detection by cDNA synthesis coupled with amplification by RT-PCR. RT- 


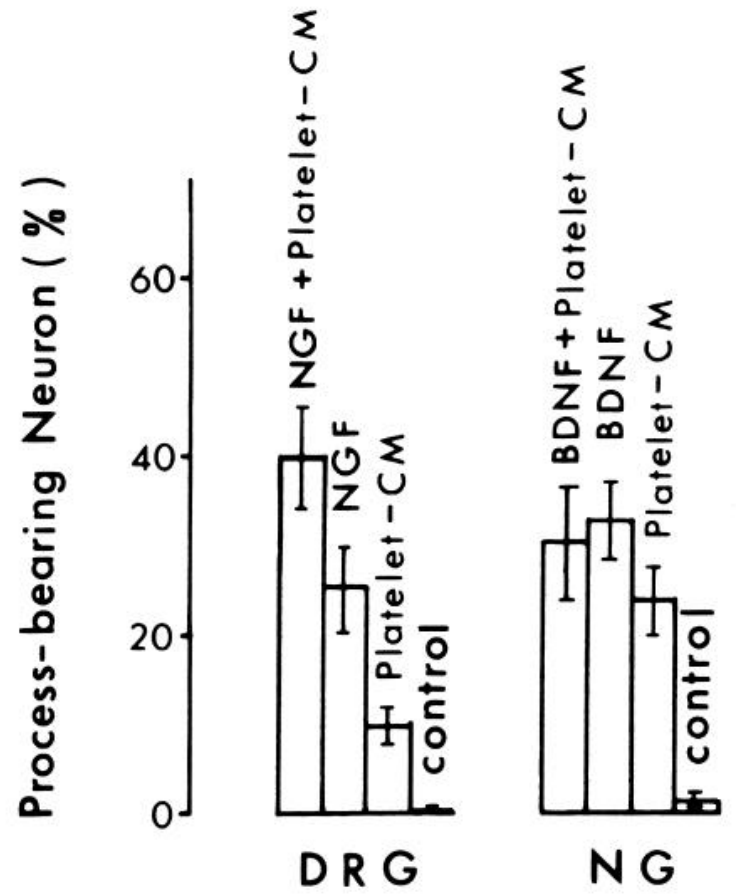

Figure 4. Platelet BDNF supports a subpopulation of E10 DRG neurons not responsive to NGF. The combination of NGF and platelet BDNF showed an additive effect on E10 DRG neurons. The combination of pig brain BDNF and platelet BDNF on E9 NG neurons was no more active than pig brain BDNF alone. Numbers of neurons with long processes were counted after $2 \mathrm{~d}$ in culture in $\mathrm{F} 14 / 10 \% \mathrm{HS}$ medium $(n=4$; values are mean $\pm \mathrm{SD})$.

PCR has allowed the molecular cloning of the cDNA encoding platelet glycoprotein IIIa (Newman et al., 1988).

In designing primers for amplifying a BDNF cDNA, we chose regions of $\mathrm{BDNF}$ sequence that we thought might be conserved between species based on its high homology to NGF. Like NGF, BDNF is synthesized initially as part of a larger precursor of 252 amino acids from an mRNA of 1184 nucleotides. Proteolytic processing occurs at a pair of dibasic residues (after $\mathrm{Arg}^{132}$ ) to liberate the amino terminus of mature BDNF. Mature BDNF contains 119 amino acids. The highest homology between pig and human BDNF was expected to be in the region of the cDNA encoding the mature factor rather than in the upstream sequences encoding the processed polypeptide precursor. The sequences of BDNF and NGF have complete identity of cysteine residues. High homology is observed within the sequences around the first cysteine residue (12 of 14 matches) and around the last cysteine residue ( 12 of 14 matches). Sequences upstream of the first cysteine codon also have low degeneracy of codon usage. These 2 regions were chosen for primary synthesis. One of the upstream, sense PCR primers (primer 2) and both of the downstream, antisense PCR primers (primers 3,4 ) successfully amplified BDNF cDNA fragments (Table 1, Fig. 6).

Detection of BDNF mRNA in human platelets was performed by cDNA synthesis with M-MLV RT followed by DNA amplification with the Taq PCR. The expected sizes of the BDNF cDNA fragments amplified by primers $2 / 3$ and $2 / 4$ are 345 and 315 base pairs (bp), respectively. As a positive control for RTPCR, we used polyA ${ }^{+}$mRNA from the mouse brain. The high level of expression of BDNF mRNA in the mouse brain detected by Northern hybridization (Leibrock et al., 1989) suggested that the hybridization signal might be due in part to BDNF mRNA expression in astrocytes. As an additional positive control for RT-PCR, therefore, we included polyA ${ }^{+}$mRNA isolated from a human astrocytoma cell line, U-87 MG. RT-PCR amplified single DNA fragments of the expected sizes from both mouse brain and U-87 MG polyA ${ }^{+}$mRNA (Fig. 7; only U-87 MG is shown). A BDNF cDNA fragment was amplified from total platelet RNA after priming the RT reaction with either random oligonucleotides or oligo dT; however, clearner PCR amplification was obtained with oligo dT-primed cDNA synthesis (Figs. $7,8)$. The result indicates that the megakaryocyte expresses BDNF mRNA and supports our identification of the neurotrophic factor in human platelets as BDNF.

Due to the high sensitivity of RT-PCR, one concern was the possible contamination of the platelet RNA with human genomic DNA. As a control, therefore, PCR amplifications of platelet RNA were performed without cDNA synthesis by M-MLV RT. No amplification of BDNF DNA was detected (Fig. 8, lane 5).
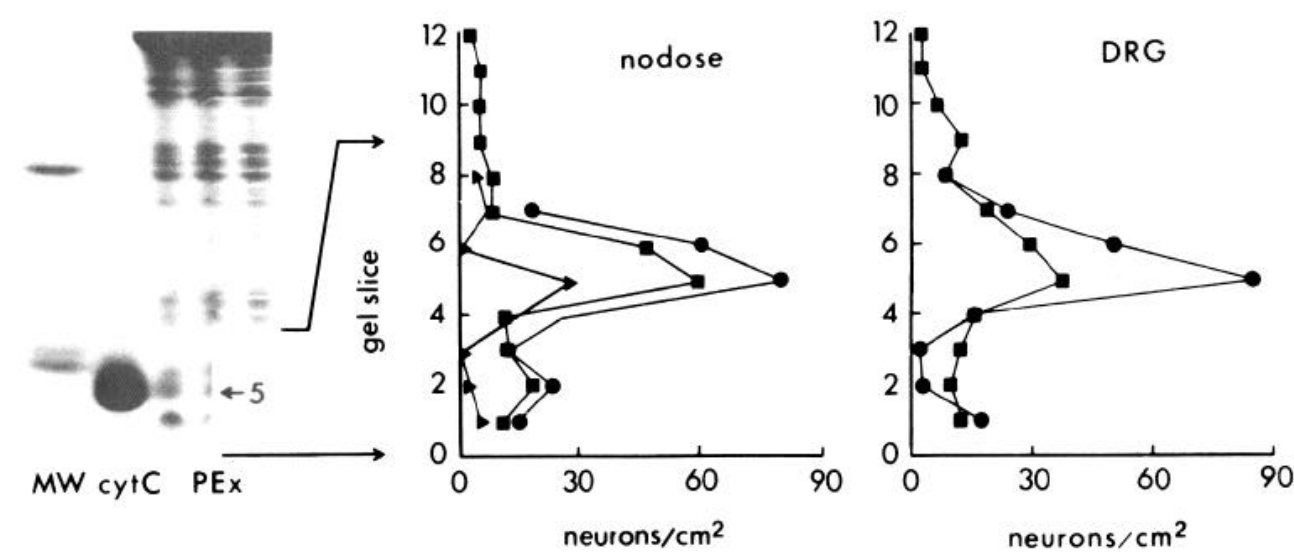

Figure 5. Fractionation of human platelet extract by SDS-PAGE on $14 \%$ acrylamide, $0.134 \%$ bis-acrylamide gels. Growth-promoting activity was assayed with E7 nodose neurons and E8 DRG neurons cultured in serum-free N1 medium lacking insulin. On the Coomassie blue-stained gel were loaded carbonic anhydrase $(29,000 \mathrm{Da}), \beta$-lactoglobulin $(18,400 \mathrm{Da})$, and lysozyme $(14,300 \mathrm{Da} ; M W$, lane 1$)$; rhodamine-conjugated cytochrome $\mathrm{C}(12,500-13,500 \mathrm{Da} ;$ cytC, lane 2), and human platelet extract (PEx, lanes 3-5) at $150 \mu \mathrm{g}$ protein per lane. The gel was sliced, and the indicated slices were extracted and tested for growth-promoting activity. Gel slices were numbered with respect to the position of the rhodamine-labeled cytochrome C (gel slice 5). Data from 4 separate experiments are shown. Neurotrophic activity co-electrophoresed with rhodamine-labeled cytochrome $\mathrm{C}$ as a single peak of identical mobility when bioassayed with either nodose or DRG neurons. 
Human NGF

Sense primer

Val Cys Asp Ser Val Ser Val Trp Val Gly

GTG TGT GAC AGT GTC AGC GTG TGG GTT GG

BDNF

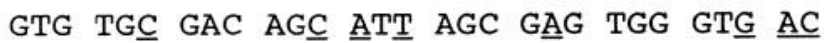

107

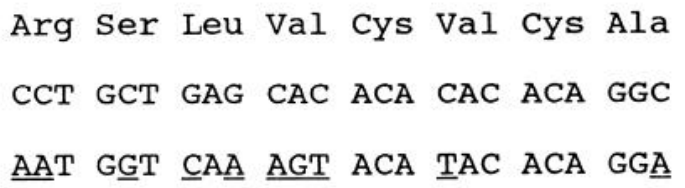

Figure 6. PCR primers for amplification of NGF sequences. The PCR primers for amplifying human NGF sequences are compared to the homologous $\mathrm{BDNF}$ nucleotide sequence. Nucleotide mismatches between BDNF and NGF are underlined.
Due to our concern that the BDNF PCR primers might also amplify a NGF cDNA because of the high homology between the 2 factors, we synthesized a set of human NGF RT-PCR primers. The regions chosen for PCR primer synthesis were regions of low homology between NGF and BDNF, but of high homology between human and mouse NGF (Fig. 6). That allowed the use of mouse salivary gland polyA ${ }^{+}$mRNA as a positive control in the RT-PCR, and strong amplification of a fragment of the expected size (303 bp) was obtained (data not shown). No NGF mRNA was detected by RT-PCR in human platelets (Fig. 8), which supports the specificity of BDNF cDNA

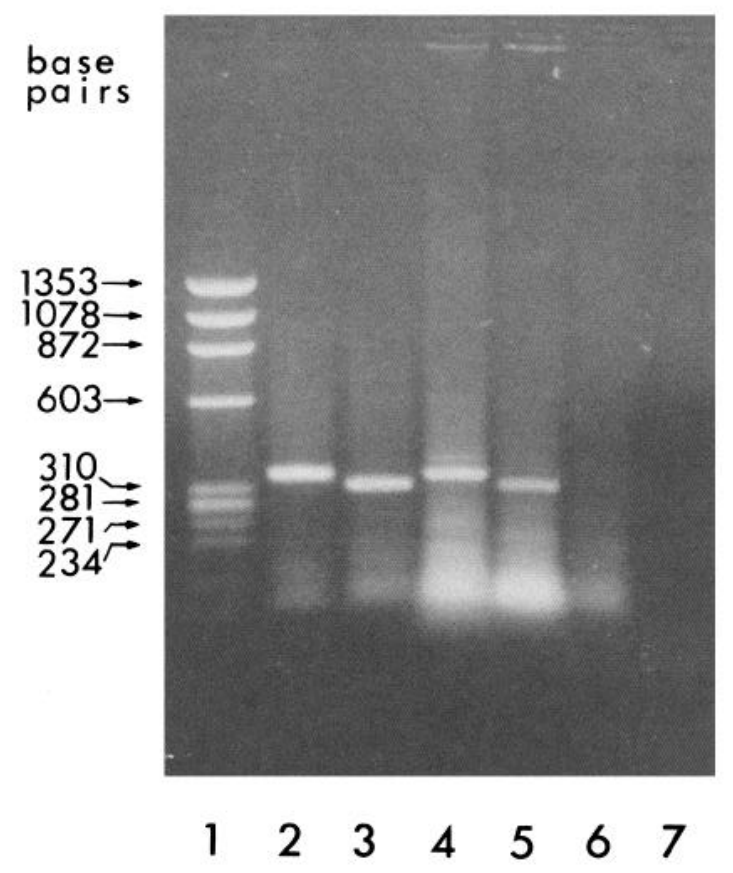

Figure 7. Detection of BDNF mRNA in human platelets and human astrocytoma cell line U-87 MG using cDNA synthesis by M-MLV RT and random oligonucleotide primer followed by DNA amplification with PCR. For the U-87 MG reactions (lanes $2,3,6$ ), $0.75 \mu$ g polyA $^{+}$ mRNA was used, and $2.3 \mu \mathrm{g}$ total RNA was used for the platelet reactions (lanes 4, 5, 7). The expected sizes of the BDNF DNA fragments amplified by the $2 / 3$ and $2 / 4$ primer pairs are 345 and $315 \mathrm{bp}$, respectively. Lane 1, Molecular weight markers are an HaeIII digest of 0X174RF DNA. Lanes 2 and 4, BDNF 2/3 primer pair. Lanes 3 and 5 , BDNF $2 / 4$ primer pair. Lanes 6 and 7 , Failure of BDNF primer pair $1 / 4$ to prime DNA amplification. amplification by the $2 / 3$ and $2 / 4$ PCR primer pairs. A weak NGF cDNA signal was detected in the U-87 MG cell line.

\section{$D N A$ sequence analysis of human $B D N F$}

To confirm that a BDNF cDNA fragment had been amplified from human platelet RNA, the 345-bp cDNA fragment amplified by PCR primer pair $2 / 3$ was cloned into M $13 \mathrm{mp} 8$ for DNA sequence analysis using dideoxynucleotides. The sequence of the 345-bp fragment amplified from both total platelet RNA (4

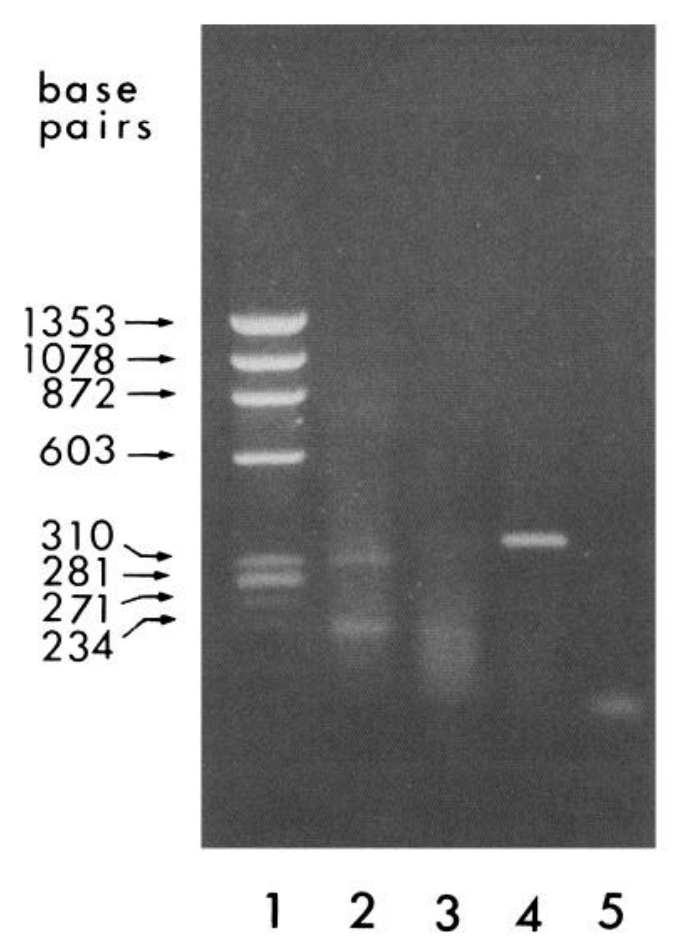

Figure 8. Detection of BDNF mRNA, but not NGF mRNA, in human platelets. An oligo dT primer and M-MLV RT were used for cDNA synthesis from total platelet RNA before amplification by PCR. Lane 1, 0X174 RF DNA HaeIII digest. Lane 2, $0.75 \mu \mathrm{g} \mathrm{U}-87$ MG polyA ${ }^{+}$ RNA was used for cDNA synthesis, then amplified by PCR with the NGF primer pair. Lanes 3 and 4, $2.3 \mu \mathrm{g}$ total platelet RNA was used for CDNA synthesis, then amplified by PCR with the NGF primer pair (lane 3) or the BDNF primer pair 2/3 (lane 4). Lane 5, Same reaction as lane 4 with the BDNF primer pair, except no RT was added to the reaction mixture. No human genomic DNA contamination was detected in the platelet RNA preparation. The size of the NGF cDNA fragment amplified by the PCR primers was expected to be $303 \mathrm{bp}$. 


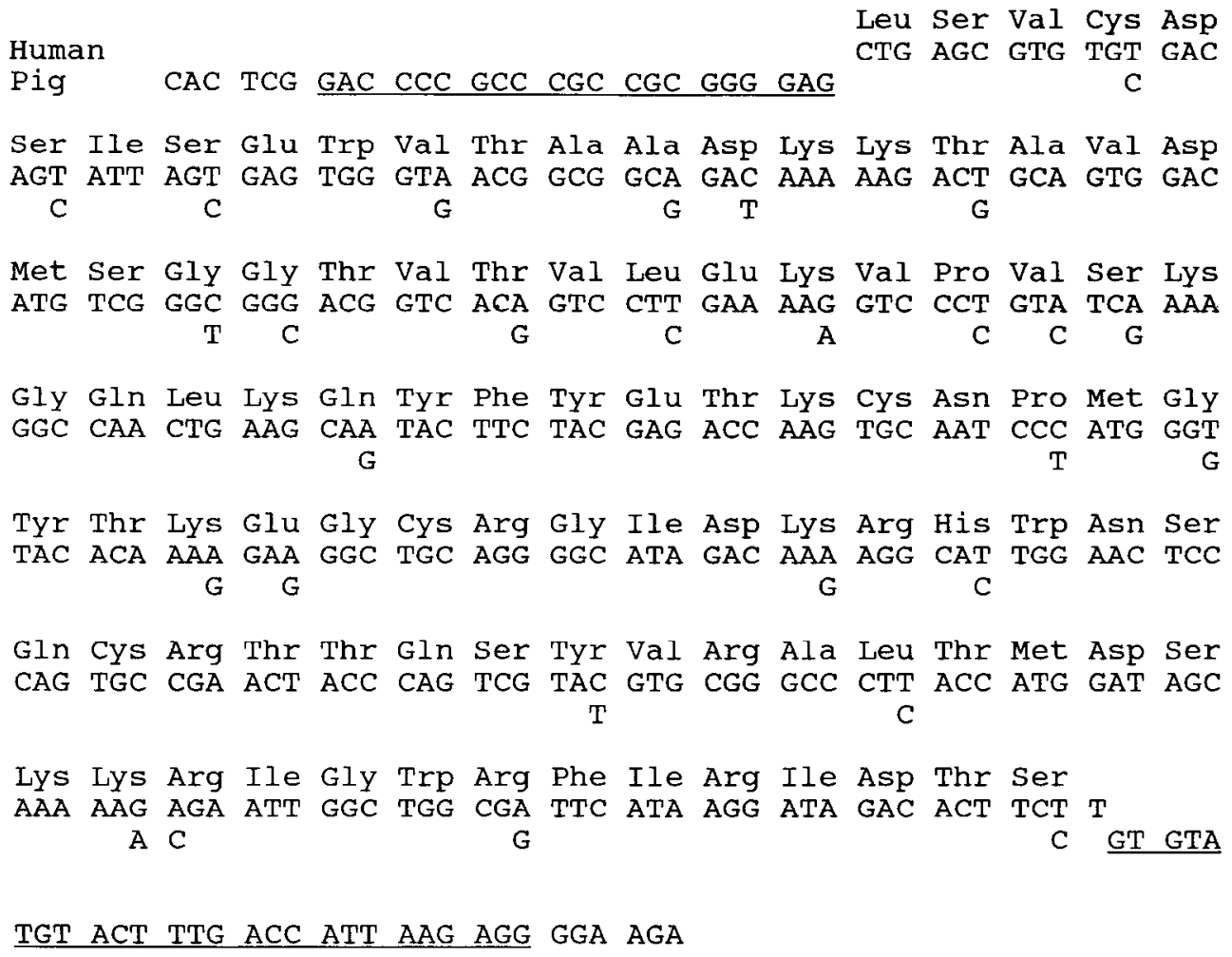

Figure 9. Nucleotide sequence and deduced amino acid sequence of human BDNF. The deduced amino acid sequence (aa 10-109) for human BDNГ between primer 2 and 3 was completely identical to pig BDNF. Only third-base substitutions ( 28 of $298 \mathrm{bp}$ ) were observed in the region of the cDNA sequenced. The sequence of BDNF primer 2 and the sequence complementary to $\mathrm{BDNF}$ primer 3 are underlined. trocytoma were identical. Complete identity of the deduced amino acid sequence was found between the human and the pig for the region sequenced (aa 10-108). Sequence homology at the nucleic acid level was $91 \%$, with most nucleotide sequence differences being third-base substitutions in codons.

The complete identity of human and pig BDNF over the region sequenced is unusual. The homology of human and bovine NGF is $95 \%$, and the homology of rabbit and rat CNTF is $83 \%$, while for the cytokines [interleukin-1 (IL-1), IL-2, etc.], homology between species can be as low as $50-60 \%$ (Oppenheim et al., 1986).

BDNF was initially characterized in rat $\mathrm{C} 6$ glioma cells and in homogenates of the adult rat brain (Barde et al., 1980). It was subsequently purified from the adult pig brain (Barde et al., 1982). BDNF expression in the brain also rises late in development when gliogenesis is occurring (Maisonpierre et al., 1990). Our observation, that BDNF mRNA is highly expressed in a human astrocytoma cell line as well as in rat C6 glioma cells (data not shown), suggests that BDNF synthesis may be predominantly by glia cells. Although highly expressed in the CNS, BDNF mRNA was undetectable by Northern hybridization in the peripheral tissues of the adult mice examined, which included the kidney, gut, liver, spleen, heart, and lung (Leibrock et al., 1989). The high expression of BDNF in the brain, but the failure to detect BDNF mRNA in peripheral tissues, supports the idea that peripheral neurons that require BDNF derive trophic support through their central process. This contrasts with NGF, for which trophic support is target derived. NGF is expressed by the target tissues innervated by sympathetic and DRG sensory neurons, and trophic support is derived via the neuron's peripheral process.

In contrast to the high dependence of embryonic neurons on trophic support derived from target tissues or the CNS, adult

\section{DRG neurons are less dependent on neurotrophic factors for}

line U-87 MG and in rat C6 glioma cells (data not shown). The partial cDNA sequences determined from platelets and the as- 
survival (Johnson and Yip, 1985). Adult DRG neurons can be placed in culture and readily survive without the addition of exogenous trophic factors to the culture medium. Although the adult neurons do not require BDNF or NGF for survival, both factors enhance axonal regeneration by the cultured neurons (Lindsay, 1988).

In addition to NGF and BDNF, another member of the NGF gene family has been identified (Hohn et al., 1990; Maisonpierre ct al., 1990). Named ncurotrophin-3 (NT-3), it has neurotrophic activity for DRG, nodose, and sympathetic neurons, in contrast to BDNF, which does not support sympathetic neurons, and in contrast to NGF, which does not support nodose neurons. NT-3 is widely expressed in most adult tissues, while expression of NGF or BDNF in adult tissues is limited (Maisonpierre et al., 1990). NT-3 expression in the brain is high during development and low in the adult, while the opposite pattern is seen for BDNF. Although exogenous BDNF will rescue nodose neurons during the period of naturally occurring cell death (Hofer and Barde, 1988), the recent data on NT-3 and BDNF expression in the embryonic brain indicates that NT-3 may be the developmentally important factor for nodose neuron trophic support.

What might be the biological role of BDNF in human platelets? Platelets are a rich source of BDNF outside of the CNS. Extracts prepared from human platelets contain approximately $50-100$ times the BDNF biological activity of porcine brain extract: $4-6 \mu \mathrm{g}$ per ml platelet extract versus $500 \mu \mathrm{g}$ per $\mathrm{ml}$ brain homogenate is required for $50 \%$ of maximal neurite outgrowth by sensory DRG neurons (Barde et al., 1982). One possibility is that BDNF has effects on non-neural tissues. Platelets contain platelet-derived growth factor (PDGF) (Ross et al., 1986) and transforming growth factor-beta (TGF- $\beta$ ) (Assosian et al., 1983), and these act in concert to promote proliferation of vascular smooth muscle cells after wounding of or damage to blood vessels (Bowen-Pope et al., 1985). A role for BDNF in the response of the vessel wall to wounding should be investigated.

Platelets also contain the amyloid $\beta$-protein precursor protease nexin-II (PN-II), whose abnormal cleavage product is deposited in neuritic plaques in Alzheimer's disease (Van Nostrand et al., 1990). PN-II is packaged in platelet $\alpha$-granules. It inhibits 2 kallikrein proteases implicated in the processing of growth factor precursors, the epidermal growth factor binding protein, and the $\gamma$-subunit of NGF, as well as factor XIa, which is part of the intrinsic pathway of blood coagulation (Van Nostrand et al., 1990). A role for PN-II in regulating the processing of the BDNF precursor in the megakaryocyte should also be considered.

In addition to being the key mediators of thrombosis and hemostasis, platelets are also immune effector cells in certain delayed-type hypersensitivity (DTH) reactions. Degranulation of both platelet and mast cells due to DTH affects vascular permeability. Mast cell degranulation is stimulated by binding of IgE to cell-surface Fc receptors, by certain components of complement, and by NGF (Bruni et al., 1982). Although mast cells normally may not be exposed to sufficient NGF to trigger degranulation in vivo, a role for BDNF released from platelets in triggering mast cell degranulation should be evaluated.

The relatively large amounts of BDNF in human platelets might also be an important source of neurotrophic support after damage to peripheral nerves and another example of the interplay between the immune system and neural cells at the site of nerve lesion. For example, transection of the sciatic nerve enhances local NGF synthesis up to 15-fold by non-neuronal cells, which include Schwann cells, epithelial cells, smooth muscle cells, and fibroblasts (Bandtlow et al., 1987; Heumann et al., 1987). Both IL-1 and PDGF can trigger local synthesis of NGF by non-neuronal cells (Lindholm et al., 1987). After traumatic disruption of the blood-nerve barrier and extravasation of blood into the endoneurium, infiltrating macrophages will be a cellular source of IL-1, while PDGF will be released from platelets. The binding of platelets to 3 components of the extracellular matrix (collagen, laminin, and fibronectin) exposed by injury is an initial event in their activation. Binding to collagen induces platelet aggregation and consequent degranulation, while binding to laminin or fibronectin does not induce activation (Ill et al., 1984). Thus, the binding of platelets to matrix components may deliver BDNF to matrix substrates that can support neurite outgrowth by regeneraating sensory neurons.

The mechanism of the release of BDNF from platelets and the possible synthesis of BDNF by non-neuronal cells at the site of peripheral nerve trauma have yet to be examined. Local NGF synthesis by non-neuronal cells at the site of nerve injury and the release of BDNF by platelets at the site of the lesion may both provide trophic support for regenerating sensory neurons. Thus, in addition to PDGF and TGF- $\beta$, which promote vascular repair, $\mathrm{BDNF}$ in platelets may be another important factor for promoting tissue regeneration.

\section{References}

Assosian RK, Komoriya A, Meyers CA, Miller DM, Sporn MB (1983) Transforming growth factor- $\beta$ in human platelets. J Biol Chem 258: $7155-7160$.

Bandtlow CE, Heumann R, Schwab ME, Thoenen H (1987) Cellular localization of nerve growth factor by in situ hybridization. EMBO J 6:891-899.

Barbin G, Manthorpe M, Varon S (1984) Purification of the chick eye ciliary neuronotrophic factor. J Neurochem 43:1468-1478.

Barde Y-A, Edgar D, Thoenen H (1980) Sensory neurons in culture: changing requirements for survival factors during embryonic development. Proc Natl Acad Sci USA 77:1199-1203.

Barde Y-A, Edgar D, Thoenen H (1982) Purification of a new neurotrophic factor from mammalian brain. EMBO J 1:549-553.

Bowen-Pope DF, Ross R, Seifert RA (1985) Locally acting growth factors for vascular smooth muscle cells: endogenous synthesis and release from platelets. Circulation 72:735-740.

Bruni A, Bigon E, Boarato E, Mietto L, Leon A, Toffano G (1982) Interaction between nerve growth factor and lysophosphatidylserine on rat peritoneal mast cells. FEBS Lett 138:190-192.

Davies AM (1987) Molecular and cellular aspects of patterning sensory neurone connections in the vertebrate nervous system. Development 101:185-208.

Davies AM, Thoenen II, Barde Y-A (1986) The response of chick sensory neurons to brain-derived neurotrophic factor. J Neurosci 6: 1897-1904.

Goedert M, Otten U, Hunt SP, Bond A, Chapman D. Schlumpf M, Lichtensteiger W (1984) Biochemical and anatomical effects of antibodies against nerve growth factor on developing rat sensory ganglia. Proc Natl Acad Sci USA 81:1580-1584.

Gorin PD, Johnson EM (1979) Experimental autoimmune model of nerve growth factor deprivation: effects on developing peripheral sympathetic and sensory neurons. Proc Natl Acad Sci USA 76:53825386.

Gurney ME, Apatoff BR, Spear GT, Baumel MJ, Antel JP, Bania MB, Reder AT (1986) Neuroleukin: a lymphokine product of lectinstimulated T cells. Science 234:574-581.

Hamburger V, Brunso-Bechtold JK, Yip JW (1981) Neuronal death in the spinal ganglia of the chick embryo and its reduction by nerve growth factor. J Neurosci 1:60-71.

Helfand SL, Smith GA, Wessels NK (1976) Survival and development in culture of dissociated parasympathetic neurons from ciliary ganglia. Dev Biol 50:541-547.

Hendry IA, Campbell J (1976) Morphometric analysis of rat superior 
cervical ganglion after axotomy and nerve growth factor treatment J Neurocytol 5:351-360.

Heumann R, Korsching S, Bandtlow C, Thoenen H (1987) Changes of nerve growth factor synthesis in nonneuronal cells in response to sciatic nerve transection. J Cell Biol 104:1623-1631

Hofer MM, Barde Y-A (1988) Brain-derived neurotrophic factor prevents neuronal death in vivo. Nature 331:261-262.

Hohn A, Lcibrock J, Bailcy K, Barde Y-A (1990) Identification and characterization of a novel member of the nerve growth factor/brainderived neurotrophic factor family. Nature 344:339-341.

Ill CR, Engvall E, Ruoslahti E (1984) Adhesion of platelets to laminin in the absence of activation. J Cell Biol 99:2140-2145.

Johnson EM Jr, Yip HK (1985) Central nervous system and peripheral nerve growth factor provide trophic support critical to mature sensory neuronal survival. Nature 314:751-752.

Johnson EM Jr, Rich KM, Yip HK (1986) The role of NGF in sensory neurons in vivo. Trends Neurosci 9:33-37.

Kalcheim C, Barde Y-A, Thoenen H, LeDouarin NM (1987) In vivo effect of brain-derived neurotrophic factor on the survival of developing dorsal root ganglion cells. EMBO J 6:2871-2873.

Korsching S, Thoenen $H$ (1983) Nerve growth factor in sympathetic ganglia and corresponding target organs of the rat: correlation with density of sympathetic innervation. Proc Natl Acad Sci USA 80: 3513-3516.

LeDouarin N (1982) The neural crest. Cambridge: Cambridge UP.

Leibrock J, Lottspeich F, Hohn A, Hofer M, Hengerer B, Masiakowski P, Thoenen H, Barde Y-A (1989) Molecular cloning and expression of brain-derived neurotrophic factor. Nature 341:149-152.

Levi-Montalcini R, Booker B (1960a) Excessive growth of the sympathetic ganglia evoked by a protein isolated from mouse salivary glands. Proc Natl Acad Sci USA 46:373-384.

Levi-Montalcini R, Booker B (1960b) Destruction of the sympathetic ganglia in mammals by an antiserum to a nerve-growth protein. Proc Natl Acad Sci USA 46:385-391.

Lin L-F H, Mismer D, Lile JD, Armes LG, Butler ET III, Vannice JL, Collins F (1989) Purification, cloning, and expression of ciliary neurotrophic factor (CNTF). Science 246:1023-1025.

Lindholm D, Heumann R, Meyer M, Thoenen H (1987) Interleukin-1 regulates synthesis of nerve growth factor in non-neuronal cells of rat sciatic nerve. Nature 330:658-659.

Lindsay RM (1988) Nerve growth factors (NGF, BDNF) enhance axonal regeneration but are not required for survival of adult sensory neurons. J Neurosci 8:2394-2405.

Lindsay RM, Thoenen H, Barde Y-A (1985) Placode and neural crestderived sensory neurons are responsive at early developmental stages to brain-derived neurotrophic factor. Dev Biol 112:319-328.

Maisonpierre PC, Belluscio L, Squinto S, Ip NY, Furth ME, Lindsay RM, Yancopoulos GD (1990) Neurotrophin-3: a neurotrophic factor related to NGF and BDNF. Science 247:1446-1451.

Manthorpe M, Skaper S, Williams LR, Varon S (1986) Purification of adult rat sciatic nerve ciliary neurotrophic factor. Brain Res 367: 282-286.

Martin DP, Schmidt RE, DiStefano PS, Lowry OH, Carter JG, Johnson EM Jr. (1988) Inhibitors of protein synthesis and RNA synthesis prevent neuronal death caused by nerve growth factor deprivation. J Cell Biol 106:829-844.

Newman PJ, Gorski J, White GC II, Gidwitz S, Cretney CJ, Aster RH (1988) Enzymatic amplification of platelet-specific messenger RNA using the polymerase chain reaction. J Clin Invest 82:739-742.

Oppenheim JJ, Kovacs EJ, Matsushima K, Durum SK (1986) There is more than one interleukin 1. Immunology Today 7:45-55.

Rodrigeuz-Tebar A, Barde Y-A (1988) Binding characteristics of brainderived neurotrophic factor to its receptors on neurons from chick embryo. J Neurosci 8:3337-3342.

Ross R, Raines EW, Bowen-Pope DF (1986) The biology of plateletderived growth factor. Cell 46:155-169.

Stockli KA, Lottspeich F, Sendtner M, Masiakowski P, Carroll P, Gotz R, Lindholm D, Thoenen H (1989) Molecular cloning, expression and regional distribution of rat ciliary neurotrophic factor. Nature 342:920-923.

Unsicker K, Reichert-Preibsch H, Schmidt R, Pettmann B, Labourdette $G$, Sensenbrenner M (1987) Astroglial and fibroblast growth factors have neurotrophic functions for cultured peripheral and central nervous system neurons. Proc Natl Acad Sci USA 84:5459-5463.

Van Nostrand WE, Schmaier AH, Farrow JS, Cunningham DD (1990) Protease nexin-II (amyloid $\beta$-protein precursor): a platelet-granule protein. Science 248:745-748.

Yip HK, Johnson EM Jr (1984) Developing dorsal root ganglion neurons required trophic support from their central process: evidence for a rolc of retrogradely transported nerve growth factor from the central nervous system to the periphery. Proc Natl Acad Sci USA 81:62456249 . 